\title{
Model Penguatan Nilai-Nilai Spiritual Dalam E-Learning Berdasarkan Standar Literasi Media Pendidikan Online
}

\author{
${ }^{1}$ Rila Setyaningsih, ${ }^{2}$ Abdullah, ${ }^{3}$ Edy Prihantoro, ${ }^{4}$ Hustinawaty \\ ${ }^{1,2)}$ Universitas Darussalam Gontor, 2Jl. Raya Siman, Km.06, Siman, Ponorogo, Indonesia, 63471 \\ ${ }^{3,4)}$ Universitas Gunadarma, Jl. Margonda Raya No. 427, Pondok Cina, Beji, Kota Depok, Jawa Barat 16424 \\ E-mail: 1rilasetya@unida.gontor.ac.id, ${ }^{2}$ abdullah@unida.gontor.ac.id, ${ }^{3}$ edipri@staff.gunadarma.ac.id, \\ 4hustina@staff.gunadarma.ac.id
}

\begin{abstract}
Abstrak: Munculnya era digital membawa berbagai perubahan dan dampak positif dalam kehidupan manusia. Di sisi lain era digital menghasilkan dampak negatif yang menjadi tantangan dalam aspek kehidupan sosial, politik, ekonomi, bahkan pendidikan. Era digital bukan persoalan siap atau tidak, bukan juga menjadi sebuah pilihan akan tetapi sudah merupakan suatu konsekuensi. Maka tidak ada pilihan lain selain menguasai dan mengendalikan teknologi dengan baik dan benar agar memberi manfaat yang sebesar-besarnya, salah satunya dengan upaya menguatkan nilai-nilai spiritual para pengguna media digital terutama dalam dunia pendidikan. Tujuan penelitian ini untuk menemukan model penguatan nilai-nilai spiritual dalam e-learning berdasarkan standar literasi media pendidikan online di Universitas Darussalam Gontor. Penelitian ini menggunakan metode kualitatif deskriptif. Pengumpulan data dilakukan melalui observasi dan wawancara dengan pemangku kebijakan di Program Studi Ilmu Komunikasi Universitas Darussalam Gontor. Hasil penelitian berupa model penguatan nilai-nilai spiritual dalam e-learning berdasarkan standar literasi media pendidikan online di Universitas Darussalam Gontor. Model penguatan nilai-nilai spiritual dalam e-learning dikaji berdasarkan tujuh standar literasi media online meliputi prinsip produksi konten, etika distribusi informasi, jaminan akurasi dan komitmen anti hoak, spirit amar ma'ruf nahi munkar, asas hikmah dalam dakwah, prinsip dalam interaksi digital, dan prinsip kebebasan. Kontribusi penelitian ini berupa model penguatan nilai-nilai spiritual dalam e-learning berdasarkan standar literasi media pendidikan online di Universitas Darussalam Gontor.
\end{abstract}

Kata kunci: model, nilai spiritual, e-learning, literasi media online

\begin{abstract}
The emergence of the digital era brought various changes and positive impacts on human life. On the other hand, the digital era has a negative impact which is a challenge in aspects of social, political, economic and even educational life. The digital age is not a matter of being ready or not, nor is it a choice but it is already a consequence. Then there is no choice but to master and control technology properly and correctly so as to provide maximum benefit, one of them is by strengthening the spiritual values of digital media users, especially in the world of education. The purpose of this study is to find a model of strengthening spiritual values in e-learning based on online education media standards at the University of Darussalam Gontor. This study uses descriptive qualitative methods. Data collection is done through observation and interviews with policy makers in the Communication Studies Program at University of Daussalam Gontor. The results of the study are models of strengthening spiritual values in e-learning based on online education media literacy standards at the University of Darussalam Gontor. The model of strengthening spiritual values in e-learning is reviewed based on seven online media literacy standards covering the principles of content production, ethics of information distribution, guarantee of accuracy and commitment of anti hoak, spirit of amar ma'ruf nahi munkar, wisdom principle in da'wah, principles in digital interaction, and the principle of freedom. The contribution of this research is a model of strengthening spiritual values in e-learning based on online education media literacy standards at the University of Darussalam Gontor.
\end{abstract}

Keywords: models, spiritual values, e-learning, online media literacy 


\section{PENDAHULUAN}

Munculnya era digital membawa berbagai perubahan dan dampak positif dalam kehidupan manusia. Teknologi menjadi alat yang mampu membantu sebagian besar kebutuhan manusia, hal ini karena teknologi dapat mempermudah manusia dalam melakukan apapun tugas dan pekerjaan (Setiawan, 2017: 1). Dalam bidang pendidikan, beberapa teknologi internet memiliki pengaruh yang cukup positif. Internet memberikan segudang informasi berkaitan dengan referensi yang dibutuhkan untuk menunjang kegiatan pembelajaran. Teknologi internet memberikan kemudahan dalam mencari berbagai informasi melalui mesin pencari dengan cepat dan real time, dimana saja dan kapan saja selama terhubung dengan jaringan.

Di sisi lain era digital menghasilkan dampak negatif yang menjadi tantangan sekaligus peluang terutama dalam bidang pendidikan, khususnya lembaga pendidikan berbasis pesantren. Lembaga pendidikan pesantren mau tidak mau harus menyesuaikan diri dengan perkembangan era digital dengan menggunakan teknologi sebagai bentuk inovasi teknologi pendidikan. Hal ini karena era digital bukan persoalan siap atau tidak, bukan juga menjadi sebuah pilihan akan tetapi sudah merupakan suatu konsekuensi. Maka tidak ada pilihan lain selain menguasai dan mengendalikan teknologi dengan baik dan benar supaya memberi manfaat yang sebesar-besarnya.

Kenyataan inilah yang harus dihadapi dunia pesantren di era digital. Di satu sisi harus berperan aktif dalam arus transformasi ilmu pengetahuan dan peningkatan nilai-nilai spiritual. Dalam hal ini pesantren harus tetap mempertahankan specific coor outcome, yaitu; keluaran yang beraqidah, berakhlak karimah dan berilmu luas (Mansur, Husaini, Mujahidin, dan Tafsir, 2016: 5). Sementara di sisi lain pesantren harus menyesuaikan diri dengan menyelenggarakan pendidikan berbasis teknologi digital. Universitas Darussalam Gontor sebagai salah satu perguruan tinggi berbasis pesantren modern telah melakukan inisiasi untuk melakukan inovasi teknologi pendidikan. Salah satu bentuk inovasi yang dilakukan berupa penggunaan e-learning dalam kegiatan pembelajaran.

Inovasi yang dilakukan Universitas Darussalam Gontor membawa perguruan tinggi pesantren tersebut untuk menghadapi kenyataan baru. Kenyataan yang dihadapi adalah tantangan dalam mengimplementasikan pendidikan dan pembelajaran menggunakan teknologi informasi dan komunikasi berupa kekagetan mental dalam menghadapi perubahan kultur belajar. Teknologi digital yang seharusnya menjadi pemicu percepatan penguasaan ilmu pengetahuan, justru menjadi penghambat. Hal ini karena terbatasnya pengetahuan mahasiswa santri dalam menggunakan situs dan blog yang berisi konten - konten ilmu pengetahuan, e-learning dan e-searching yang memungkinkan mahasiswa santri mengakses ilmu pengetahuan. Tantangan lain berupa keberadaan e-learning dengan sistem pembelajaran virtual menjadikan dosen tidak dapat mengontrol langsung dan intensif kegiatan mahasiswa terutama terkait dengan penguatan nilai-nilai spiritual mahasiswa dan pemberian uswah hasanah. Hal yang paling penting adalah bahwa pesantren harus mampu mempertahankan tujuan utama pendidikan, sebagaimana yang dirumuskan Departemen Agama Republik Indonesia; "pendidikan dalam sebuah pesantren bertujuan untuk mempersiapkan pemimpin-pemimpin akhlaq dan keagamaan. Diharapkan bahwa para santri akan pulang ke masyarakat mereka sendiri untuk menjadi pimpinan tidak resmi di masyarakatnya" (Mansur, Husaini, Mujahidin, dan Tafsir, 
2016: 7).

Ada beberapa penelitian yang sudah dilakukan dengan fokus pemanfaatan teknologi informasi dan komunikasi dalam dunia pendidikan pesantren. Pada tahun 2012, Sholihah melakukan penelitian tentang peran ICT (Information, Communication and Technologi) dalam modernisasi pendidikan pondok pesantren (Sholihah, 2012: 15-28). Hasil penelitian menunjukkan bahwa kekuatan ICT telah mendorong terjadinya perubahan dalam pembelajaran. Pemanfaatan ICT pada pembelajaran memberikan banyak keuntungan, baik bagi santri, ustadz, maupun pengelola pesantren. Pemanfaatan ICT dapat meningkatkan efisiensi dan efektivitas proses pembelajaran dan pengelolaan pesantren. Di samping itu, dengan ICT akan memperluas dan meningkatkan dakwah syiar islam dan pendidikan masyarakat. Penelitian lain dilakukan oleh Mansur, Husaini, Mujahidin, dan Tafsir (2016: 1-25) dengan tujuan untuk meningkatkan model pengajaran karakter kejujuran menggunakan teknologi informasi dan komunikasi di pesantren. Hasil penelitian menunjukkan bahwa model pengajaran kejujuran menggunakan teknologi informasi dan komunikasi sangat berpengaruh signifikan terhadap internalisasi nilainilai kejujuran. Sebagaimana dikonfirmasi oleh hasil Paired T-Test (T-Test Berpasangan) terhadap nilai rata-rata sebelum dan sesudah treatment. Penelitian tentang penguatan nilai-nilai religius di perguruan tinggi pernah dilakukan oleh dengan hasil penelitian menunjukkan bahwa penguatan nilai-nilai religius ditanamkan Fakultas Ilmu Komunikasi Universitas Islam Bandung di setiap lini kehidupannya mulai dari kurikulum, sumber daya manusia (tenaga pendidik, tenaga kependidikan, dan mahasiswa), maupun lingkungan kerja (setting), dan menjadikan nilai-nilai islami sebagai yang tak terpisahkan dengan pekerjaan dan pelayanan. Kesemuanya terintegrasi di dalam satu sistem, demi terciptanya penguatan nilai yang menjadi tujuan bersama (Yulianti, Hamdan, dan Putri, 2018: 177-187).

Sejalan dengan ketiga penelitian terdahulu, penelitian ini berusaha untuk menggali lebih jauh tentang pemanfaatan ICT berupa e-learning sebagai sarana untuk meningkatkan nilai-nilai spiritual di perguruan tinggi berbasis pesantren modern. Nilai-nilai spiritual merupakan nilai yang terdapat dalam kejiwaan manusia yang mencakup nilai estetika, nilai moral, nilai religius dan nilai kebenaran. Menurut Agustian (2008) menghadirkan spiritualitas dalam pendidikan akan memberi makna besar terhadap kehidupan bangsa, keyakinan terhadap keberadaan Tuhan akan menimbulkan komitmen kuat untuk selalu memberikan yang terbaik untuk bangsa (Murdiono, 2010: 99-111). Lebih jauh, penelitian ini berusaha untuk menemukan sebuah model penguatan nilai-nilai spiritual dalam e-learning di perguruan tinggi pesantren.

2003 Undang-undang No.20 Tahun Nasional menyatakan bahwa pendidikan adalah usaha sadar dan terencana untuk mewujudkan suasana belajar dan proses pembelajaran agar peserta didik secara aktif mengembangkan dirinya untuk memiliki kekuatan spiritual keagamaan, pengendaliandiri,kepribadian, kecerdasan akhlak mulia, serta keterampilan yang diperlukan dirinya, masyarakat, bangsa, dan negara (Jenkins, 2010). Hal ini menunjukkan bahwa penguatan nilai spiritual dalam pendidikan perlu dilakukan secara terencana. Demikian juga proses pembelajaran dengan model virtual class melalui e-learning harus mampu menciptakan suasana belajar yang mampu mendorong peserta didik untuk tetap mampu mengembangkan 
nilai spiritual. Dalam konteks ini, upaya peningkatan nilai spiritual santri dapat dilakukan dengan terlebih dahulu menguatkan nilai-nilai spiritual para dosen sebagai pemberi tauladan bagi para mahasiswa santrinya.

$$
\text { Penguatan nilai-nilai spiritual }
$$
dalam e-learning dalam penelitian ini dikaji berdasarkan standar literasi media online yaitu prinsip produksi konten, etika distribusi informasi, jaminan akurasi dan komitmen anti hoak, spirit amar ma'ruf nahi munkar, asas hikmah dalam dakwah, prinsip dalam interaksi digital, dan prinsip kebebasan. Penelitian ini penting dilakukan untuk menemukan model penguatan nilia-nilai spiritual dalam e-learning di Universitas Darussalam Gontor. Hal ini mendukung kebijakan pemerintah yang tercantum dalam undang-undang No.20 Tahun 2003 tentang Sistem Pendidikan Nasional.

\section{METODE}

Penelitian ini menggunakan metode deskriptif kualitatif untuk menemukan model penguatan nilai-nilai spiritual dalam e-learning di Universitas Darussalam Gontor. Data dalam penelitian ini diperoleh melalui observasi secara langsung serta wawancara mendalam. Observasi dilakukan dengan melakukan pengamatan secara langsung kegiatan pembelajaranmelaluie-learning. Kegiatan observasi merupakan salah satu kegiatan untuk memahami lingkungan (Ardianto, 2010:179). Wawancara mendalam (dept interview) adalah teknik mengumpulkan data atau informasi dengan informan agar mendapatkan data lengkap dan mendalam. Wawancara ini dilakukan dengan frekuensi tinggi (berulang-ulang) secara intensif (Ardianto, 2010:178). Wawancara dalam penelitian ini dilakukan dengan pemangku kebijakan di UNIDA Gontor yang terdiri dari Dekan Fakultas Humaniora, Kepala program studi Ilmu Komunikasi UNIDA Gontor, dan sekretaris program studi. Wawancara dilakukakan secara mendalam tentang upaya penguatan nilai spiritual dalam pembelajaran melalui e-learning.

Setelah melakukan observasi dan wawancara mendalam, peneliti mengonstruksi pesan-pesan yang diperoleh dari informan dan memetakan upaya penguatan nilai-nilai spiritual dalam e-learning melalui standar literasi media pendidikan online. Teknik analisis data dilakukan berdasarkan teori Miles dan Huberman yaitu reduksi data, penyajian data, dan penarikan kesimpulan atau verifikasi data (Idrus, 2009: 180). Reduksi dilakukan dengan cara merangkum, memilih hal-hal yang pokok, dan memfokuskan pada hal-hal yang penting. Penyajian data dalam bentuk uraian singkat, bagan, hubungan antar kategori, flowchart dan sejenisnya. Penarikan kesimpulan/ verifikasi merupakan alur ketiga dalam teknik analisis data setelah reduksi dan penyajian data.

Keabsahan data penelitian dilakukan dengan triangulasi. Menurut Sugiono (2010) triangulasi adalah teknik pengumpulan data yang bersifat menggabungkan dari berbagai teknik dan sumber data yang ada. Triangulasi data dalam penelitian ini menggunakan triangulasi metode yang dilakukan dengan cara menggabungkan teknik observasi dan wawancara serta observasi untuk mengumpulkan data tentang model penguatan nilai-nilai spiritual melalui e-learning. Triangulasi sumber berarti membandingkan dan mengecek balik derajat kepercayaan suatu informasi yang diperoleh (Moleong, 2009:330331). Untuk menguji keabsahan data yang diperoleh dalam penelitian, penulis melakukan observasi ke lapangan secara mendalam. Data dari hasil penelitian yang diperoleh melalui wawancara dengan para narasumber selanjutnya diuji keabsahan datanya dengan melakukan observasi 
langsung kepada dekan, kepala program studi, sekeretaris program studi dan dosen di lingkungan Ilmu Komunikasi UNIDA Gontor. Penulis pun mengamati setiap aktivitas yang dilakukan dalam kegiatan pembelajaran mata kuliah dasar ilmu komunikasi berbasis e-learning. Penulis mengamati dan menganalisis hasil wawancara dengan pendapat dekan, kepala program studi, sekeretaris program studi dan dosen mengenai penguatan nilai-nilai spiritual dalam e-learning berdasarkan standar literasi media pendidikan online yang terdiri dari tujuh standar.

\section{PEMBAHASAN}

Penelitian ini menemukan model penguatan nilai-nilai spiritual dalam e-learning melalui standar literasi media pendidikan online yang dilakukan Universitas Darussalam Gontor. Standar literasi media online memiliki tujuh komponen yaitu prinsip produksi konten, etika distribusi informasi, jaminan akurasi dan komitmen anti hoak, spirit amar ma'ruf nahi munkar, asas hikmah dalam dakwah, prinsip dalam interaksi digital, dan prinsip kebebasan. Tujuh standar literasi media islam online merupakan standar literasi media yang digagas oleh Ditjen Bimas Islam Kementrian Agama bekerjasama dengan Komisi Informasi dan Komunikasi Majelis Ulama Indonesia. Dalam penelitian ini, objek penguatan nilai-nilai spiritual dalam e-learning adalah dosen sebagai uswah dan teladan bagi para mahasiswa santri di Universitas Darussalam Gontor.

Standar pertama prinsip produksi konten adalah langkah verifikasi (tabayyun) akurasi informasi dan cermat memeriksa kredibilitas narasumber. Berpegang pada kaedah "ambil yang jernih, buang yang keruh" harus menjadi pegangan dalam memilah dan memilih informasi yang dijadikan materi dalam pembelajaran, mengingat realitas saat ini dimana informasi di era media baru sangat bervariasi jenis dan sifatnya. Dosen menggunakan referensi yang terpercaya dan akurat dalam materi yang diupload dalam portal e-learning. Mencantumkan sumber daftar pustaka yang relevan untuk menghindari kesalahan. Selain itu, memberbanyak komparasi sumber informasi yang kredibel dilakukan untuk memperoleh informasi yang mendalam dan utuh. Hal ini sejalan dengan penelitian Bashori dan Syafri (2016: 163183) tentang studi kritis konsep sanad kitab najh al-balaghah sebagai upaya membangun budaya tabayyun dalam keilmuan islam. Dalam penelitiannya Bashori dan Syafri menyatakan bahwa tabayyun atau tatsabbut atau tahaqquq (verifikasi) dan taakkud (konfirmasi) dalam berita adalah penting agar kita tidak berbuat salah, zalim dan menyesal. Salah satu rekomendasi penelitiannya adalah agar kegiatan tabayyun ilmiah digalakkan supaya menjadi biasa dan membudaya sebagai ciri khas Ahlussunnah wa alJamaah.

Standar kedua etika distribusi informasi adalah memastikan bahwa informasi yang akan disebar membawa manfaat dan tidak memicu perdebatan. Dalam penelitian ini, dosen sebagai subjek penelitian selalu memastikan kebermanfaataninformasi dan materiyang disampaikan melalui e-learning. Langkah yang dilakukan berupa penyusunan silabus dan satuan acara perkuliahan yang di sahkan oleh ketua program studi, dan selalu di evaluasi pada akhir perkuliahan untuk memastikan bahwa materi yang disampaiakan benar-benar membawa manfaat bagi para mahasiswa santri. Berkaitan dengan masalah etis dalam media online Margianto dan Syaefullah (2006: 33) menyatakan bahwa kehadiran internet sebagai medium baru dengan segala implikasi praktisnya, memunculkan ketegangan baru di ranah etis. 
Standar ketiga jaminan akurasi dan komitmen anti hoak adalah menajamin kejujuran informasi ditengah informasi dusta, hoax, dan manipulatif. Secara historis dan etimologi kita dapat menelusuri. Hoax adalah term yang berasal dari abad ke-18. Penelusuran menunjukkan bahwa term hoax memiliki relasi langsung dengan Hocus yang memiliki arti "menipu", "memaksa pada" atau merujuk pada Merriam-Webster "kebingungan yang dimulai dari minuman yang sudah diracuni. Sedari awal, hoax memiliki atribusi negatif, membuat orang termanipulasi atau tertipu atasu suatu hal (Adiprasetio, Justito. Gumilar, Gumgum, 2017). Dosen di UNIDA Gontor telah memiliki komitmen untuk menyebarkan informasi yang akurat dan menghindari segala bentuk hoax. Materi yang di sampaikan melalui e-learning merupakan informasi yang mengandung kejujuran.

Standar keempat spirit amar ma'ruf nahi munkar adalah prinsip kontrol untuk menyeru kebajikan dan mencegah kemungkaran. Dosen UNIDA Gontor memiliki semangat amar ma'ruf nahi munkar dalam semua kegiatan di asrama baik dalam kelas maupun diluar kelas. Dalam kegiatan pembelajaran melalui e-learning, materi yang disampaikan merupakan materi umum yang dipadukan dengan worldview islam, sehingga spirit amar ma'ruf nahi munkar merupakan tujuan utama dalamkegiatan pembelajaran dengan goal perubahan sosial. Strategi dan metode dakwahpun disesuaikan dengan kondisi di era digital saat ini, dalam penelitian ini berupa dakwah melalui media online e-learning. Hal ini sejalan dengan penelitian Amran (2012: 68-86) tentang dakwah dan perubahan sosial. Hasil penelitian menunjukkan bahwa pelaksanaan dakwah harus menerapkan metode dan strategi baru yang dikaitkan dengan kondisi sosial yang ada dalam masyarakat agar fungsi dakwah dapat berjalan dengan efektif dalam masyarakat dalam upaya membentengi umat dari pengaruhpengaruh negatif dari akibat perubahan sosial yang terjadi dalam masyarakat.

Standar kelima asas hikmah dalam dakwah adalah mengedepankan sikap bijak, penuh hikmah, keteladanan yang baik, jika harus berdebat maka dilakukan dengan cara yang lebih baik. Dosen UNIDA Gontor telah berupaya untuk menjadi teladan yang baik bagi para mahasiswa santri, menasehati dengan cara yang baik. Dalam konteks pembelajaran online banyak hal yang telah dicontohkan misalnya menghindari plagiarisme, disiplin dalam pembelajaran, dll. Hal ini sebagaimana penelitian Ghafur (2014: 236) tentang dakwah bilhikmah di era informasi dan globalisasi berdakwah di masyarakat baru. Menurut Ghafur, gerakan dakwah di era global sudah sejatinya menyuguhkan content, bukan hanya secara konvensionaltradisional, tapi secara modern dengan menggunakan IT, sehingga menjangkau sasaran dakwah yang luas, melintas batas dengan isi yang sesuai dengan kebutuhan dan tantangan masyarakat baru yang kompleks dan dengan penuh kedalaman, meski bernuansa praktis.

Standar keenam prinsip dalam interaksi digital adalah saling respek dan berspirit saling membantu (ta'awun). Dalam konteks UNIDA Gontor, seluruh dosen dan mahasiswa santri telah terbiasa untuk saling menghormati dan membantu satu dengan lainnya. Kegiatan menghormati dan membantu dalam proses pembelajaran melalui e-learning dapat ditunjukkan dengan adanya forum diskusi yang menyediakan kesempatan seluas-luasnya untuk saling bertukar pendapat. Respek merupakan salah satu nilai spiritual yang penting untuk dikembangkan di berbagai kelompok masyarakat.

Standar ketujuh prinsip kebebasan adalah menyampaikan informasi 
dengan cara mengekspresikan secara bertanggungjawab dengan berpegang pada prinsip "manusia terbaik adalah yang paling bermanfaat bagi sesama manusia. Dalam konteks di UNIDA Gontor, penyampaiakn materi dilakukan dengan bebas tetapi tetap secara bertanggungjawab dan bertujuan untuk memberikan keberkahan bagi orang lain. Hal ini sebagaimana disampaikan Watie (2011:69-75) bahwa media online semakin membuka kesempatan tiap individu yang terlibat di dalamnya untuk bebas mengeluarkan pendapatnya. Akan tetapi kendali diri harusnya juga dimiliki, agar kebebasan yang dimiliki juga tidak melanggar batasan dan tidak menyinggung pihak lain.

Tujuh standar literasi media islam online merupakan standar yang dapat digunakan untuk menguatkan nilai-nilai spiritual dalam pembelajaran e-learning yang dilakukan di UNIDA Gontor. Berdasarkan hasil analisis ditemukan sebuah model penguatan nilai-nilai spiritual dalam e-learning yang disajikan dalam GAMBAR 1.

GAMBAR 1 merupakan model penguatan nilai-nilai spiritual dalam e-learning di Universitas Darussalam Gontor yang dilakukan melalui proses pembelajaran. Komunikator yang terdiri dari para pengampu mata kuliah dasar menyampaiakan pesan (konten pembelajaran) kepada komunikan (peserta kuliah) melalui media e-learning. Dengan mengaplikasikan tujuh standar literasi media islam online maka

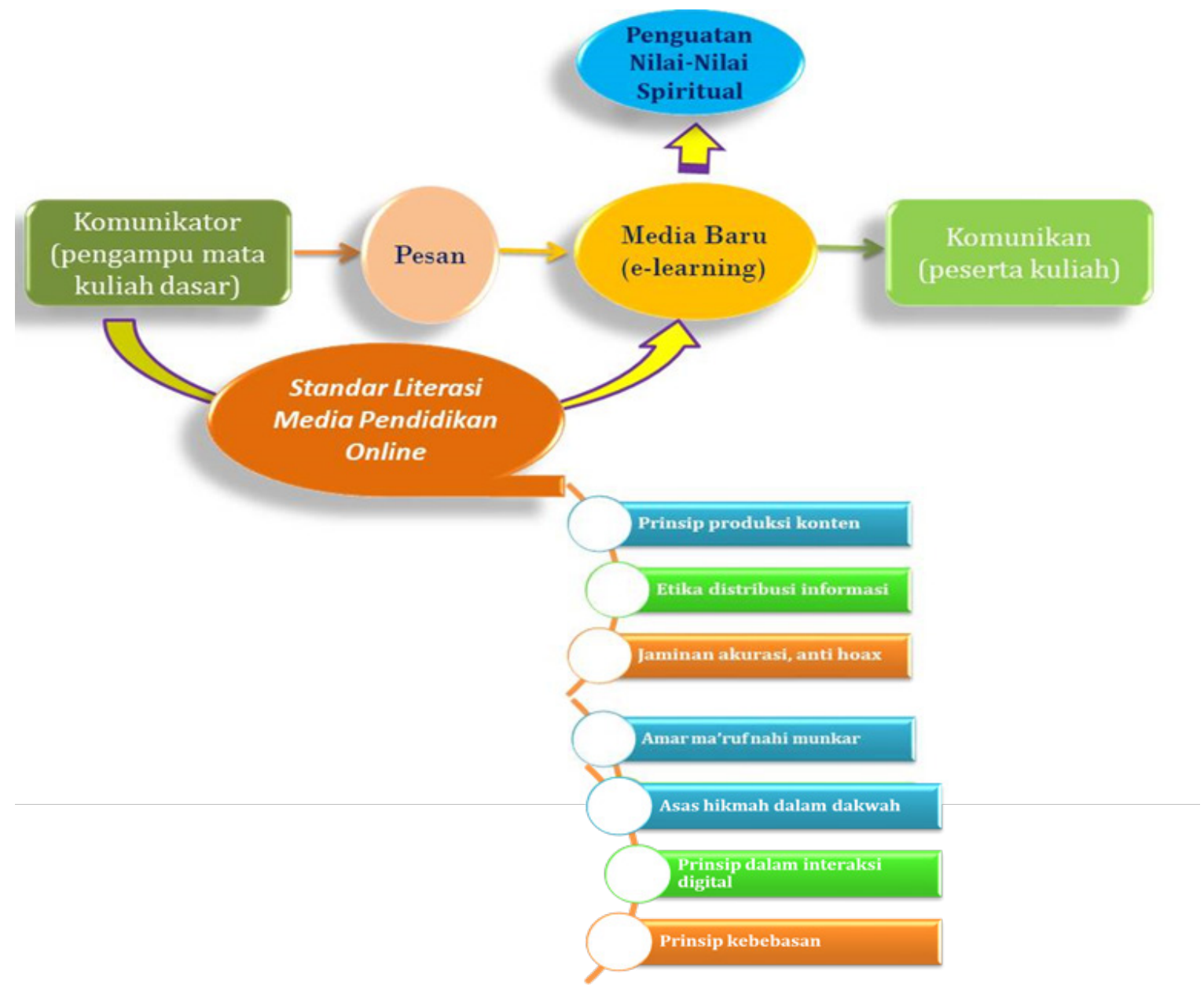

GAMBAR 1. Model penguatan nilai-nilai spiritual dalam e-learning

(Sumber: data peneliti 2018) 
hal itu merupakan upaya penguatan nilai-nilai spiritual dalam e-learning. Kebaruan dalam penelitian ini berupa pengembangan model pembelajaran e-learning yang dapat dijadikan sebagai model penguatan nilai-nilai spiritual.

\section{SIMPULAN}

Penelitian ini menemukan sebuah model penguatan nilai-nilai spiritual dalam e-learning di Universitas Darussalam Gontor. Penguatan nilai-nilai spiritual dalam e-learning di Universitas Darussalam Gontor dikaji berdasarkan tujuh standar literasi media islam online. Tujuh standar literasi media islam online meliputi prinsip produksi konten, etika distribusi informasi, jaminan akurasi dan komitmen anti hoak, spirit amar ma'ruf nahi munkar, asas hikmah dalam dakwah, prinsip dalam interaksi digital, dan prinsip kebebasan. Kontribusi penelitian ini berupa model penguatan nilai-nilai spiritual dalam e-learning di Universitas Darussalam Gontor melalui standar literasi media islam online.

\section{DAFTAR PUSTAKA}

Adiprasetio, Justito. Gumilar, Gumgum, H. dan N. M. (2017). HOAX, REPRODUKSIDAN PERSEBARAN: SUATU PENELUSURAN LITERATUR. Jurnal Pengabdian Kepada Masyarakat, 1(4), 271-278.

Amran, Ali. (2012). Dakwah dan Perubahan Sosial. Jurnal Hikmah, VI(1), 68-86.

Ardianto, Elvinaro. (2010). Metode Penelitian Untuk Public Relatios Kuantitatif Dan Kualitatif. Bandung: Simbiosa Rekatama Media.

Bashori, Agus Hasan dan Syafri, Ulil Amri. (2016). Studi Kritis Konsep Sanad Kitab Najh Al-Balaghah Sebagai Upaya Membangun Budaya Tabayyun Dalam Keilmuan Islam. El Harakah,
18(2), 163-183.

Ghafur, Waryono Abdul. (2014). Dakwah Bil-Hikmah Di Era Informasi Dan Globalisasi Berdakwah Di Masyarakat Baru. Jurnal Ilmu Dakwah, 34(2), 236258.

Jenkins, Peggy Joy. (2010). Mengembangkan Nilai-Nilai Spiritual Pada Anak. Jakarta: Gramedia Pusaka.

Mansur, AH; Husaini, Adian; Mujahidin, Endin dan Tafsir, Ahmad. (2016). Model Pengajaran Karakter Kejujuran Menggunakan Teknologi Informasi dan Komunikasi. Ta'dibuna Jurnal Pemikiran Islam, 5(1), 1-25.

Margianto, J.Heru dan Syaefullah, Asep. (2006). Media Online: Pembaca, Laba, dan Etika: Problematika Praktik Jurnalisme Online di Indonesia. Majalah Pusat Dokumentasi ELSAM. Jakarta: AJI Indonesia.

Moleong, Lexy. (2009). Metode Penelitian Kualitatif. Bandung: PT. Remaja Rosda Karya.

Murdiono, Mukhamad. (2010). Strategi Internalisasi Nilai-Nilai Moral Religius Dalam Proses Pembelajaran Di Perguruan Tinggi. Cakrawala Pendidikan, Mei 2010, Th. XXIX, Edisi Khusus Dies Natalis UNY, 99111.

Setiawan, Wawan. (2017). Era Digital dan Tantangannya. Prosiding Seminar Nasional Pendidikan 2017, ISBN.978602-50088-0-1.

Sholihah, Ummu. (2012). Peran ICT Dalam Modernisasi Pendidikan Pondok Pesantren. Cendekia, 10(1), 15-28.

Undang-undang No.20 Tahun 2003 tentang Sistem Pendidikan Nasional

Watie, Errika Dwi Setya. (2011). Komunikasi dan Media Sosial. The Messenger, III(1), 69-74.

Yulinti; Hamdan, Stephani Raihana; Putri, Dian Widya. (2018). MediaTor, Vol 11 (2), 177-187. 